\title{
Analysis of house prices: a hedonic model proposal for Istanbul metropolitan area
}

\author{
Kerem Yavuz Arslanl1* (D)
}

\begin{abstract}
The purpose of this paper is to explore the nature of housing price differences in Istanbul Metropolitan Area. Factors that affect house prices in Istanbul are investigated by Hedonic Regression Model with spatial variables. House Price taken in natural Log form as dependent variable and house characteristics, neighborhood characteristics and transportation infrastructure taken as independent variables. Location of houses on Europe continent has more impact on value than Asian part of the city as the Istanbul city spread out new neighborhood areas are also developed with new characteristics. And those houses are sold according to amenities they surrounded by are spatially autocorrelated. House prices are examined in Istanbul by taking into consideration sub-market characteristics to identify localized factors. In the model distance to green areas, ports, proximity to metro stations, shopping malls, hospitals have positive but insignificant; proximity to earthquake fault lines, public bus transportation, industrial zones have negative and significant effect on prices.
\end{abstract}

Keywords: house prices, hedonic modelling, neighborhood characteristics, pricing analysis, Istanbul

\section{Introduction}

House prices and its spatial distribution are important for metropolitan areas. Prices are affected by house characteristics as well as submarket conditions in space and time. Location factors are heterogeneous distribution of house prices studied in different aspects of House Unit properties, Neighborhoods effects and location factors (Dokmeci, 1996). Aim of this paper is to analyze the distribution of house prices within Istanbul metropolitan area which has a very dynamic structure and to determine factors affecting each housing submarket.

Wide literature and research on house price dynamics and indexes in developed countries. Early studies on real estate price index construction, repeated sales of same properties on utility information to single family houses (Bailey, Muth, Nourse, 1963). In repeated sales regression model repeated sales of same property generally represents small portion of house market and new and rapid urbanization could not be represented by model. Neighborhood Dynamics (Can, 1990) and spatial dependence of house price indices and spillover effects of comparable sales are important factors (Can, Megbolugbe,1997). Spatial component over house price indexes are very important in explaining house price distribution of houses over time and space frequency and

* (Corresponding author) Assoc. Prof. Dr. İstanbul Technical University Turkey, \$arslanli@itu.edu.tr This is an open access research article under the CC BY NC license

Article history: Received 04 Nov. 2020, Accepted 14 Dec. 2020, Published 29 Dec. 2020. 
pattern effects prices (Gelfand, Ecker, Knight, Sirmans, 2004) Incorporate with spatial dependence and Location matters, spatial autocorrelated error terms (Dubin, 1998; Basu, Thibodeau, 1998;).

Hedonic and Spatial-Temporal models are mostly employed to explain the housing markets. Repeated Sales approach to hedonic models since 1967 many contributions made by distinguished academics. After developing technologies on computer systems and Geographical Information Systems spatial interaction in housing market is widely discussed and studied among geographers and economics. Before economics try to avoid spatial autocorrelation as the geographers consider it to valuable information to investigate through. Fast and huge data computing capabilities of GIS system made those spatial autocorrelations be observed and modeled for better outcomes. The housing markets are temporally auto-correlated due to its nature of habit. The monthly prices of houses are affected by the previous months and many research support seasonality among house prices. To avoid this temporal autocorrelation AR models used to correct seasonality in the works of many academics. For spatial autocorrelation the main issue is that house prices are affected by near sales of residential units but the form function of near or neighbor effect differs among academics. Krigging and negative exponential functional form employed to explain interaction between house prices. Neighbor and submarket clustering among housing market on the other hand revealed reduced standard error terms. The difficulty of defining the submarket borders also another issue to define and aggregate.

Spatial Autocorrelation in hedonic modeling used to utilize in works of Clapp which are lagged in time and space to form a local regression model. In which to define time and space asymmetries other than hedonic model cannot utilize (Clapp, 2003). LRM model requires the assumption that the underlying space-time has smooth surface. House prices and the transaction data over time is related in the research that structural change in the macroeconomic status rather than the cyclic measures in prices (Andrew, 2003). Problems that are associated with the hedonic house price modeling that measuring house characteristics are hard to collect and expensive to obtain. Even some characteristics are omitted this causes error in the estimates. Repeated sales approach on the other hand requires more dataset to explain hose prices and assumption on the same house within timeline that represents small amount of market (Haurin 1991). Non-parametric regression a technique that is to calculate the price indexes in Meese and Wallace that locally weighted regression model is to construct an index without assuming the same functional form everywhere (Haurin, 1991) Quality improvements are accounting for much of the house price in the repeated indexes as the median based quantile estimator in the produced more accurate estimators in study on city of Chicago (McMillen, 2003).

Another external factor that affects the house prices in the market is found to be physical constraints, population, income and demographic variables (Malpezzi, 1997). Comparing among the house price index methodologies that hedonic, repeated sales found to have bias and inefficiency of the prices or the market and Hybrid model found to be avoiding these problems. But systematical differences between single and repeated transacted houses generates bias in all 3 models (Case, Pollakowski, 1991) House Prices and its spatial distribution are important for metropolitan areas. Prices are affected by house characteristics as well as submarket conditions in space and time. Location factors are heterogeneous distribution of house prices studied in different aspects of House Unit properties, Neighborhoods effects and Location factors (Dokmeci, 1994). Aim of this paper is to analyze the distribution of house prices within Istanbul metropolitan area which has a very dynamic structure and to determine factors affecting each housing submarket.

Many studies have been conducted to examine hedonic house price modeling. Maximum likelihood estimation to house prices with a residual autocorrelation found to be negative exponential form of distance between properties (Dubin 1988). Spatially lagged values are introduced by Can (1997) into model to explain house prices. A spatio-temporal auto regressive model for multi-unit residential market is analyzed (Sun, 2005) found that Bayesian estimation process is found to get better results than conventional OLS estimation. Long run house price index 
is examined by Eicholtz (1997) that repeated sales of same residential units enable quality constant house price index. A semi parametric method for estimating local house price indices by Clapp (2004) using 3-dimensional space-time grid to estimate each point outcome performances has reduced out-of-sample mean squared errors compared to OLS. A varying parameters approach to construct house price index by Knight (1995) used both repeated sales data and single sale transactions while contributing more information of market on estimation process. Predicting spatial patterns of house prices using Bayesian smoothing is used by Clapp (2002) access to CBD and other neighborhood amenities. Bayesian framework gives hedonic framework better results in spatial variations. The measurement and determinant of single-family house prices and found the demographic factors that affect with recovering of market after-tax interest rates and lower unemployment rates (Peek and Wilcox 1991). The spatial proximity of metropolitan area housing submarkets (Goodman \& Thibodeau, 2007) discuss the spatially adjacent neighborhood assumption for housing consumers could vary in metropolitan market. Findings suggest that performance of dwelling size as well as control variation for public school quality or provision of public safety. Spatially proximate within market yields better results but outcome is significantly higher mean squared prediction error.

House prices in Istanbul are spatially auto correlated as the same characteristic settlements build up around same areas. House properties are similar to the surrounding characteristics. As the Istanbul city spread out new neighborhood areas are also developed with similar characteristics. And those houses are sold according to amenities they surrounded by again spatially auto correlated. Government public service buildings and many like hospitals and local government offices are located around old parts of Istanbul those same houses use these facilities that affect the price.

As the hedonic model that proposed in this paper first stage residuals that are calculated are found to be spatially auto correlated. Many of the spatial characteristics are calculated after the public data is spatially located on the Cartesian coordinate system. Distance to active green space, distance to shoreline, distance to main highway entry nodes (other than distance to highways), distance to nearest public administrative facilities and nearest distance to railways and sea transportation port were calculated for the second phase of spatial model. For Istanbul identifying the neighborhood boundaries are much difficult process. Old part of the city has mostly divided by sub districts where new neighborhoods cover half of the historical peninsula with only one sub district. The main distinguishable border that city has is the Bosporus line that divides the city into two parts. Which the old city on the European side has majority (\%68 of housing units) of residential property. The old city walls that surrounds historical peninsula also clear identifier of neighborhood boundaries. But other than that, it is very hard to find elsewhere in the city. As this is the main difficult part to formulate hedonic price model on the other hand Istanbul has no official house price index calculated before. Even with the ordinary least squares methods that eventually lead to spatially autocorrelation one cannot find any price index for Istanbul metropolitan area or any kind of house price index for turkey. As the proposed models first phase conducted in this paper OLS has spatially autocorrelation that violates the assumptions of residual statistics and $t$ values to higher degrees.

\section{Background for Istanbul}

Previously analysis of residential prices in Istanbul at metropolitan level sub-market, floor area and Seaview; at district level location, socio economic factors and property characteristics are found important factors (Ozus, et al. 2007). Transformation of Istanbul CBD as the new highways and bridges across Europe and Asia has taken the importance of old historical peninsula to new developing sub-centers. As transformation of its economy into require more modern office buildings. Construction of new peripheral highways contributed to a poly-centric development of Istanbul (Dokmeci, 1994). House price volatility examined to and findings suggest several outcomes 
that Istabul, Ankara and Izmir reveal different patterns. Istanbul showed lower and insignificant house price volatilities (Coskun, 2016).

Research on Housing values and rents for Istanbul revealed that green areas around property highly affects both value and rent. On the other hand, access to transportation and shopping facilities has only affect rent values for Istanbul. Also, spatial factors have more effect on rent than prices in district level (Dokmeci, 2000). Another research on housing market for public perception of earthquake risk found distance from fault lines is important factor explaining house values and increased after 1999 earthquake (Onder, 2004).

Hedonic analysis of house prices in Istanbul results reveal that living area size, low story building, secured site and age of building affected the market. Also, income of household, earthquake risk of area and neighborhood satisfaction has an effect on residential prices (Keskin, 2008). Residential location preferences according to demographic characteristics of Istanbul study reveal that in contract with other western studies that strong desire for mobility in middle and older age groups. While young people preferences concentrated in the periphery, where large percentage of middle and old people prefer to move to intermediate between core and periphery where most easily accessible zone in the city (Dokmeci, 2000).

Determinant of house prices in Istanbul with a quantile regression approach found that age, cable tv, security, heating system, garage, kitchen area, number of rooms and bathroom increases the house prices (Caglayan, 2009). Another research on house price determinants in Istanbul using classification and regression tree (CART) approach found that house size, elevator, security, central heating unit is the most important factors among 31 variables (Özsoy, 2009).

Istanbul has the largest population in Turkey and between 1950 and 2018, its population increased from $1,002,085$ to 14.018 .735 , primarily due to rural migration. It is also the largest economic, cultural and tourism center in Turkey. While Istanbul accounts for 15 percent of Turkey's population, the share of its GNP is 22.1 percent of Turkey's GNP (State Institute of Statistics, 2019). Post 1980s, witnessed an increase in service sector as a result of economic restructuring, development of transportation and telecommunication systems, and globalization which all played an important role in the multi-center development of Istanbul as in the other large cities of the world (Heikkila et.al. 1989). These new sub-centers were furnished with modern retail facilities, office buildings and supported with modern housing complexes fitting for the middle- and upperincome groups supporting the growth of sub centers. Multi-center development of the city not only contributed to the decentralization of jobs and population but also effects house prices. Especially, large suburban sub-centers that rival the traditional $C B D$ in size and scope have significant effects on suburban spatial structure as firms and households bid for nearby sites (McMillen and Lester, 2003).

The distribution of population associated with house prices and they can be investigated by taking into consideration the development of the city during different time periods. The core area covers up to $3 \mathrm{~km}$. from the center, which corresponds to the old CBD with a 3000 year of history and has since been continuously redeveloped. While this zone used to account for 33 percent of service employment and 13 percent of manufacturing employment in 1985, these ratios decreased to 13.5 and 4 percent in 2002, respectively (State Institute of Statistics, 2002). In 2000, this zone held 13.75 percent of the city's GNP, and only 3 percent of the city's population (State Institute of Statistics, 2000). The core area is connected to the periphery by metro, rapid train, buses and ferries and thus, it has the highest pedestrian traffic due to its unique central location and being a major traffic exchange node. Its population has continuously decreased due to the area's transformation from housing into business. After the 1980s, with the help of national and international revitalization projects, it has continued to be an active business center due to its central strategic location. 


\section{Hedonic House Price Specification}

House price is in the market is determined by house characteristics. These are grouped into 1 Housing characteristics (Number of Rooms, Car parking space etc.), 2 distances to neighborhood amenities (distance to green areas, distance to highway entry nodes etc.) General function of house price is given,

$$
P=f(H, N, t)
$$

Where $\mathrm{P}$ is the sales price of property, $\mathrm{H}$ denotes variables describing house characteristics are of unit in square meters, number of baths, heating system etc., $\mathrm{N}$ denotes for distance of the unit to neighborhood amenities like distance to shopping centers, distance to CBD etc. and t denotes for time period that house unit is sold. In the model semi log function is employed in order to regress the log transformation of prices on linear formulation of housing characteristics. It is well addressed in literature that a prediction error that tends to be larger in absolute value as the property values increases. The semi log functional form is given by

$$
V=e^{\wedge}(X \beta+\varepsilon)
$$

Where $\mathrm{V}$ is property value, $\mathrm{X}$ is a vector of housing characteristics, $\mathrm{b}$ is a vector of unknown hedonic coefficients, and $\varepsilon$ is the residual. When the residual variance is constant and the residuals are spatially uncorrelated, ordinary least squares (OLS) yields best, linear, unbiased estimators of the parameters in the transformed equation.

House prices in Istanbul are spatially autocorrelated as the same characteristic build up around similar locations. As the Istanbul city spread out new neighborhood areas are developed with new characteristics. And those houses are sold according to amenities surrounded by again spatially autocorrelated. Government public service buildings and many like hospitals and local government offices are located around old parts of Istanbul those same houses use these facilities that affect the price. As the hedonic model that proposed in this paper first stage residuals that are calculated are found to be spatially auto correlated. Distance to active green space, distance to shoreline, distance to main highway entry nodes (other than distance to highways), distance to nearest public administrative facilities and nearest distance to railways and sea transportation port were calculated for the second phase of spatial model.

For Istanbul identifying the neighborhood boundaries is much difficult process. Old part of the city has mostly divided by sub districts where new neighborhoods cover half of the historical peninsula with only one sub district. The main distinguishable border that city has is the Bosporus line that divides the city into two parts. Which the old city on the European side has majority (\%68 of housing units) of residential real estate. The old city walls that surrounds historical peninsula also clear identifier of neighborhood boundaries. But other than that it is very hard to find elsewhere in the city. As this is the main difficult part to formulate hedonic price model. Even with the ordinary least squares methods that eventually lead to spatially autocorrelation for Istanbul metropolitan area. As the proposed models first phase conducted in this paper OLS has spatially autocorrelation that violates the assumptions of residual statistics and $t$ values to higher degrees.

In this paper 5303 transactions data were examined both single-family and condominiums in Istanbul Metropolitan Area. 29 sub districts were defined by submarkets hedonic model is calculated that spatial autocorrelation is detected. Asian continent market found to be less spatially correlated than European continent as general terms historical part and new CBD is located on the European part of the city. The proposed spatial statistics most of the areas that has autocorrelation is improved afterwards. Distribution of housing units in Istanbul and sampling of model selection explained in Figure 1. Princes Islands has been excluded from the dataset due to fewer sampling points. 


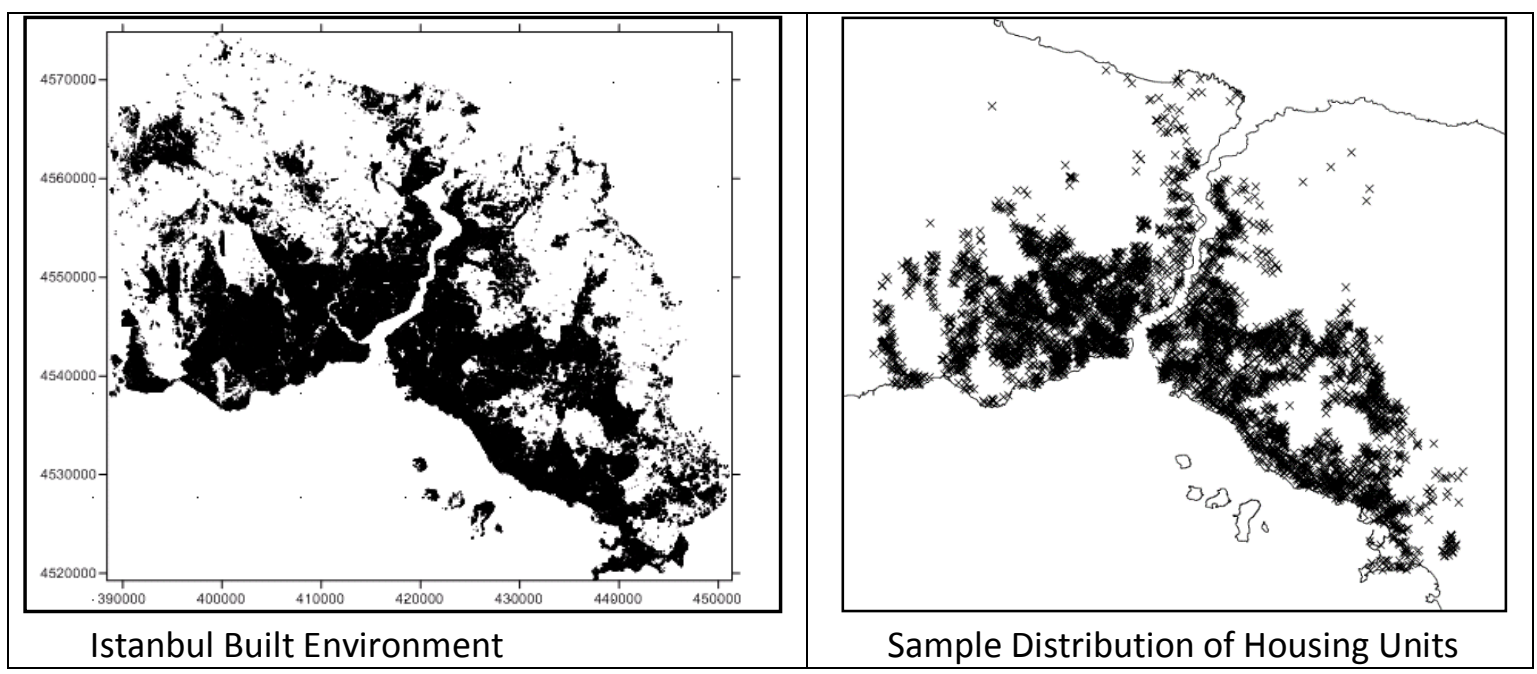

Figure 1 Housing Units and Sampling Distribution

The house prices are collected in Turkish Lira (TL) and converted into US dollars at the exchange rate of from Central Bank of Turkish Republic. Prices are transformed in natural logarithmic function as widely accepted in previously modeling of house prices. PRC_LN as coded in the model has mean value of 12,078 and standard deviation of 0,4528 . The room mean value is 2,75 with a standard deviation of 0.7927 . The mean value of house age is 11.57 and with a standard deviation of 11,04 . The FLOOR is which house is located 2.98 mean value to 2,01 standard deviation. The SQMT is area of house in square meters 122.76 mean value to 39.91 standard deviation. The BFLOOR is floor number of building that house is located 5.34 mean value to 2.39 standard deviation. BATH is the number of baths in house 1.26 mean value with 0.478 standard deviation. The DST_HWY is Distance to highway connection nodes in meters 1539,29 mean value to 1749,75 standard deviation. DST_PORT is distance to Public Sea transportation nodes in meters 4822.65 and 3087.92 standard deviation. DST_GREN is distance to public active green areas/Parks in meters 2517,84 mean value with 3104.71 standard deviation. DST_FLT is distance to Active Fault lines in meters 16417.85 mean value with 4943.43 standard deviation. DST_ADM is distance to nearest public administration buildings in meters has mean value of 4013.23 and 3357.31 standard deviation. CARPARK is 1 if house has a private car park; 0 otherwise. SEAVIEW is 1 if house has sea view, 0 otherwise. METRO is 1 if house has access to metro stations, 0 otherwise. PUBLIC is 1 if house has access to public transportation, 0 otherwise. ELAV is 1 if house has elevator system, 0 otherwise. SECU is 1 if house has security, 0 otherwise. GENERA is 1 if house has electric generator, 0 otherwise. SHOP is 1 if house is located near shopping mall, 0 otherwise. HOSP is 1 if house is located near hospital, 0 otherwise. INDUST is 1 if house located near industrial site, 0 otherwise. BALCO is 1 if the house has balcony, 0 otherwise. $X$ and $Y$ is the coordinates of house in decimal degrees. $H_{-}$TYPE is type of house if condominium is 1 , attach multi-family is 2 , detached single family is 3 .

The variables in Table 1 are coefficients between log transformation of house prices. Public transportation is negative correlated with price. This could be an indicator of only having public transportation is decreasing house price as keeping every other variable constant. This finding is also supported by the previous research the public transportation is negative effect on house prices (Özsoy 2009). Distance to sea transportation and active green areas are also negative correlation that indicates as the distance to green space and sea transportation increases the house prices. Distance to administrative buildings has a negative correlation that administrative also attracts commercial activity which also has negative effect on house prices. 
Table 1 Housing characteristics

\begin{tabular}{llll}
\hline \hline Variables & Mean & Std. Deviation & N \\
PRC_LN & 12,0783 &, 4528 & Log form of Sale Price in Dollars \\
ROOM & 2,75 &, 793 & Number of Rooms \\
AGE & 11,58 & 11,041 & Age of dwelling \\
FLOOR & 2,98 & 2,010 & Floor level of dwelling \\
HEAT &, 18 &, 384 & $=1$ if dwelling has central heating, \\
SQMT & 122,76 & 39,916 & Area of dwelling in squaremeters \\
CARPARK &, 46 &, 498 & $=1$ if dwelling has car park, 0 otherwise \\
SEAVIEW &, 21 &, 407 & $=1$ if dwelling has seaview, 0 otherwise \\
BFLOOR & 5,34 & 2,391 & Number of total floors of building \\
BATH & 1,26 &, 478 & Number of total bathrooms in dwelling \\
SEATR &, 03 &, 159 & $=1$ if dwelling is near sea transportation, 0 otherwise \\
ELAV &, 43 &, 495 & $=1$ if dwelling has Elevator, 0 otherwise \\
SECU &, 45 &, 498 & $=1$ if dwelling has Security, 0 otherwise \\
GENERA &, 07 &, 253 & $=1$ if dwelling has Electric Generator, 0 otherwise \\
BALCO &, 71 &, 454 & $=1$ if dwelling has Balcony, 0 otherwise \\
H_TYPE & 2,58 &, 866 & 3 for multistory, 2 for attached, 1 for detached housing \\
\hline
\end{tabular}

Variables in Table 2 shows another expected outcome of correlation table is that distances to Active Fault Lines of Earthquake zone also little but negative effect that as the distance increases the price of house increases too. $X$ and $Y$ coordinate values also positive effect that house price increases as $X$ decreases as a sign of European zone has higher prices than Asian part of the city. Mean distance to Fault Lines are 16,417 meters, Administrative buildings 4013 meters and Highway entrance points os 1539 meters which is almost 3 times less than sea port distance of 4822 meters and Green areas of 2517 meters of distance has been found in the sample units.

Table $2 \mathrm{X}, \mathrm{Y}$ Coordinates and neighborhood amenities distances

\begin{tabular}{llll}
\hline \hline Variables & Mean & Std. Dev & N \\
X & 416879,05 & 12917,053 & X coordinates of Dwelling in decimal degrees \\
Y & 4542992,38 & 7230,896 & Y coordinates of Dwelling in decimal degrees \\
DST_PORT & 4822,65 & 3087,921 & Distance of dwelling to nearest Seaports in Meters \\
DST_GREEN & 2517,84 & 3104,713 & Distance of dwelling to nearest Green Area in Meters \\
DST_FLT & 16417,85 & 4943,436 & Distance of dwelling to nearest Geological Fault Lines \\
DST_ADM & 4013,23 & 3357,310 & Distance of dwelling to nearest Administrative Buildings \\
DST_HWY & 1539,29 & 1749,751 & Distance of dwelling to nearest Highway Entrance \\
\hline
\end{tabular}

In the model in order to identify the Istanbul housing market spatial and temporal aggregated data is sampled using 0.05 confidence interval and \%1 error terms. Spatially aggregated building data of 2.5 million geo-coded house database is randomly selected and stored both for Europe and Asia separately. Due to the geographically uniqueness of Istanbul the Bosporus line that divides city has to be considered. 6000 points are selected randomly on geo-coded dataset and quarterly sale information to nearest selection point is aggregated. After random selection of 6000 points. The main housing stock of Istanbul is not equally divided into two continents so the rate of random selection is match with existing stock. According to state institute of statistics there are 3.391 .752 housing units is in Istanbul and \%65 percent of them are in Europe and \%35 is located in Asia. The random selection of points is weighted according to \% 65-\% 35 distributions. After geo-coded points selected and data is reduced according to assumptions of the model. Prices that are more than $\$ 400.000$ and below $\$ 50.000$, square meters higher than 300 less than 45 , room number more than 
10, building age more than 85 years, are eliminated from model calculations. After points were eliminated finally 5303 housing units remained.

The house prices were collected from local real estate brokers' sales database of 2018. In fiscal terms the brokerages fees are $\% 3$ of sales price both $\% 1.5$ from seller and buyer share. In order to taxation values up to \%48 of income gains from property many owners avoid to declare the real prices. The prices of houses that are sold by real estate brokers are collected on street level of geocoded address code. Aggregated data also cross check and outliers eliminated from each quarter period calculated separately. After collecting house prices and attributes general outline of aggregated data used to form price index function. Normal distribution of LogPrices has been tested and plotted in Figure 2 and found to be in boundries of normality. Also the most sensitive explanatory variable of housing area to log Price has been found to be in linear formation.

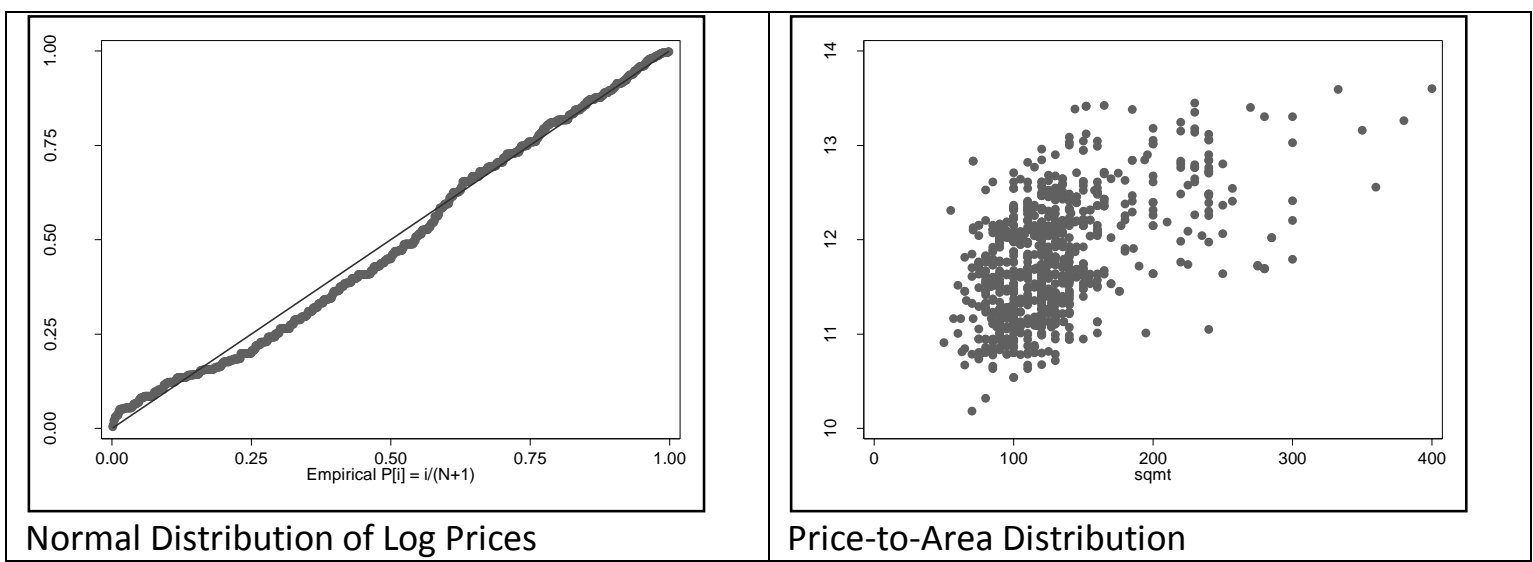

Figure 2 Log price to normal distribution and price to housing area scatter distribution

Model:

Hedonic function is important as the form of the hedonic model than in general terms:

$$
P=f(S \beta, N \gamma)+\varepsilon
$$

$P$ is the observed house prices; $S$ is the matrix of properties of observed houses (house age, area of house, number of baths etc.), $\mathrm{N}$ neighborhood unit's environment and social-economical quality matrix, $\beta, \gamma$ are the parameter vectors of the qualities and $\varepsilon$ is random error term. At this point the hedonic model and its characteristics are very important that affects the model. In many model function form is taken as linear and parameter vectors are with an independent from covariance error terms $\sigma\left(\varepsilon_{i}, \varepsilon_{j}\right)=0$ and homoscedastic $\left(\sigma^{2}\left(\varepsilon_{i}\right)=\sigma^{2}\right)$ (Can,1997).

As the dataset spatial and temporal form $\sigma\left(\varepsilon_{i}, \varepsilon_{j}\right)=0$ assumption cannot be met and this is referred in literature as spatial dependence or spatial autocorrelation. House Price Model variables are examined and outliers and assumptions of regression model in general terms the model;

$$
\ln \left(V_{i, t}\right)=\beta_{0}+\beta_{1} \text { Area }+\beta_{2}
$$




$$
\begin{aligned}
& \text { LnPrice }=\beta x_{1}+\beta x_{2}+\beta x_{3} . .+\varepsilon \\
& \sum_{k=1}^{n} \text { LnPrice }+\sum_{k=1}^{m} \beta x_{m} \\
& \log p=\beta_{0}+\sum_{j=1}^{K} \beta_{j} X_{j}+\varepsilon
\end{aligned}
$$

Where $\mathrm{p}$ Log transformed of house prices in US dollars, Bo is the constant term, By is the attributes of houses $A x$ on hedonic function and $E$ is error term with $v=0$ in normal distribution. Model at table 3 is run with 31 variables and R square is 0.5338 to Adjusted R Square 0.5286 . The standard error of Estimate is 0.3108 . As the Durbin-Watson statistics 1.310 there is evidence of positive serial correlation among datasets. Table 4 for model residuals found to be zero mean and standard deviation of 0.3. and standard residual mean also found to be zero mean and 0.99 standard deviation. In Table 5 Model coefficients are found that; Room, Age, Land Title, Car Park, Metro, Elevator, Generator, Distance to Highway, and Distance to Fault Line has found to be significant and positive effects, Public Bus Transportation and Near Industry Areas has significant

\begin{tabular}{|c|c|c|c|c|c|c|}
\hline \multicolumn{7}{|c|}{ Model Summary } \\
\hline & $\mathrm{R}$ & $\mathrm{R} 2$ & Adjusted R2 & Std. Error & Change Statistics & \\
\hline \multicolumn{5}{|c|}{ Model } & R Square Change & F Change \\
\hline \multirow[t]{2}{*}{1} & 0,730 & 0,533 & 0,528 & 0,310 & 0,533 & 101,829 \\
\hline & \multicolumn{6}{|c|}{ Table 4 Model residual statistics } \\
\hline \multicolumn{7}{|c|}{ Residuals Statistics } \\
\hline & & Minimum & Maximum & Mean & Std. Deviation & $\mathrm{N}$ \\
\hline \multicolumn{2}{|c|}{ Predicted Value } & 11,040 & 12,971 & 12,077 & 0,330 & 5303 \\
\hline \multicolumn{2}{|c|}{ Residual } & $-0,943$ & 0,884 & $-0,000$ & 0,309 & 5303 \\
\hline \multicolumn{2}{|c|}{ Std. Predicted Value } & $-3,137$ & 2,700 & $-0,002$ & 0,999 & 5303 \\
\hline \multicolumn{2}{|c|}{ Std. Residual } & $-3,033$ & 2,844 & $-0,000$ & 0,994 & 5303 \\
\hline
\end{tabular}
and negative effect on prices.

Table 3 Model summary

\section{Conclusion}

Factors that affect house prices in Istanbul are investigated by regression analysis with spatial variables. House Price taken in natural Log form as dependent variable and house characteristics, neighborhood characteristics and transportation infrastructure taken as independent variables. Data obtained from local real estate brokers and by the help of geographical information systems and spatial statistics this paper figures a distribution of house prices.

Location of houses on European continent has more impact on value than Asian part of the city. In the model number of rooms has slightly less affects prices with $P$ values 0.318 . If the house unit on rent, price is negatively effects -0.1842 . Public transportation accessibility only houses have negative -0.1256 coefficients. Proximity to shopping centers and hospitals also has positive effects on house price. House prices in Istanbul are spatially auto correlated as the same characteristic settlements build up around same areas. House properties are similar to the surrounding characteristics. As the Istanbul city spread out new neighborhood areas are also developed with similar characteristics. And those houses are sold according to amenities they surrounded by again spatially auto correlated. Government public service buildings and many like hospitals and local 
government offices are located around old parts of Istanbul those same houses use these facilities that affect the price.

The house prices were collected from local real estate brokers' sales database of 2018. In fiscal terms the brokerages fees are $\% 3$ of sales price both $\% 1.5$ from seller and buyer share. In order to taxation values up to $\% 48$ of income gains from property many owners avoid to declare the real prices. The prices of houses that are sold by real estate brokers are collected on street level of geocoded address code. Aggregated data also cross check and outliers eliminated from each quarter period calculated separately. After collecting house prices and attributes general outline of aggregated data used to form price index function. House prices are examined in Istanbul by taking into consideration sub-market characteristics to identify localized factors. Conditions to construct a robust house price model for Istanbul examined. Hedonic Regression models employed using ordinary least squares (OLS) to estimate house price. Findings of this study suggest that House Price Indices (HPI) to be studied deeply in different market segments sub-market characteristics and local factors. Further research is suggested by increasing sample size and size of spatial variables on estimating house price indexes

Table 5 Model Coefficients

\begin{tabular}{|c|c|c|c|c|c|c|c|}
\hline & \multicolumn{2}{|c|}{ Unstandardized Coefficients } & \multirow{2}{*}{$\begin{array}{l}\text { Std Coefficients } \\
\text { Beta }\end{array}$} & \multirow[t]{2}{*}{$\mathbf{t}$} & \multirow[t]{2}{*}{ Sig. } & \multicolumn{2}{|c|}{ Collinearity Statistics } \\
\hline & B & Std. Error & & & & Tolerance & VIF \\
\hline Constant & $-4,961$ & 3,593 & & $-1,380$ & 0,167 & & \\
\hline ROOM & 0,019 & 0,009 & 0,034 & 2,189 & $0,028^{*}$ & 0,354 & 2,819 \\
\hline AGE & 0,001 & 0,000 & 0,027 & 2,481 & $0,013^{*}$ & 0,742 & 1,346 \\
\hline FLOOR & $-0,001$ & 0,002 & $-0,005$ & $-0,522$ & 0,601 & 0,766 & 1,304 \\
\hline HEAT & $-0,184$ & 0,023 & $-0,156$ & $-7,976$ & 1,840 & 0,231 & 4,313 \\
\hline LAND & 0,042 & 0,014 & 0,029 & 2,862 & $0,004^{*}$ & 0,811 & 1,232 \\
\hline CONDO & $-0,007$ & 0,010 & $-0,007$ & $-0,717$ & 0,473 & 0,818 & 1,221 \\
\hline SQMT & 0,000 & 0,000 & 0,028 & 1,761 & 0,078 & 0,328 & 3,044 \\
\hline CRPARK & 0,041 & 0,012 & 0,046 & 3,431 & $0,000 *$ & 0,493 & 2,024 \\
\hline SEAVIE & 0,366 & 0,023 & 0,328 & 15,355 & 4,430 & 0,193 & 5,159 \\
\hline BFLOOR & $-0,002$ & 0,002 & $-0,014$ & $-1,139$ & 0,254 & 0,564 & 1,770 \\
\hline BATH & 0,017 & 0,010 & 0,018 & 1,604 & 0,108 & 0,694 & 1,439 \\
\hline METRO & 0,024 & 0,011 & 0,022 & 2,110 & $0,034 *$ & 0,781 & 1,279 \\
\hline PUBLIC & $-0,022$ & 0,011 & $-0,021$ & $-2,073$ & $0,038 *$ & 0,819 & 1,220 \\
\hline SEATR & 0,001 & 0,028 & 0,000 & 0,037 & 0,970 & 0,906 & 1,102 \\
\hline ELAV & 0,028 & 0,012 & 0,030 & 2,297 & $0,021^{*}$ & 0,491 & 2,034 \\
\hline SECU & $-0,014$ & 0,011 & $-0,016$ & $-1,239$ & 0,215 & 0,529 & 1,889 \\
\hline GENERA & 0,052 & 0,019 & 0,029 & 2,700 & $0,006 *$ & 0,740 & 1,349 \\
\hline SHOP & 0,022 & 0,019 & 0,012 & 1,159 & 0,246 & 0,820 & 1,218 \\
\hline HOSP & 0,103 & 0,020 & 0,053 & 5,136 & 2,909 & 0,822 & 1,216 \\
\hline INDUST & $-0,071$ & 0,023 & $-0,032$ & $-3,074$ & $0,002^{*}$ & 0,811 & 1,232 \\
\hline UNIV & $-0,044$ & 0,065 & $-0,006$ & $-0,675$ & 0,499 & 0,951 & 1,050 \\
\hline GREEN & 0,007 & 0,018 & 0,004 & 0,431 & 0,665 & 0,826 & 1,209 \\
\hline BALCO & $-0,017$ & 0,010 & $-0,017$ & $-1,716$ & 0,086 & 0,873 & 1,144 \\
\hline DSTHWY & 5,796 & 2,490 & 0,022 & 2,332 & $0,019 *$ & 0,963 & 1,037 \\
\hline$x$ & $-1,994$ & 5,420 & $-0,056$ & $-3,679$ & $0,000 *$ & 0,371 & 2,689 \\
\hline $\mathbf{Y}$ & 3,924 & 7,750 & 0,062 & 5,062 & 4,207 & 0,579 & 1,724 \\
\hline DSTPORT & $-3,952$ & 2,060 & $-0,269$ & $-19,738$ & 1,083 & 0,476 & 2,097 \\
\hline DSTGRN & $-2,967$ & 2,450 & $-0,203$ & $-12,131$ & 2,330 & 0,316 & 3,163 \\
\hline DSTFLT & 3,389 & 1,040 & 0,037 & 3,253 & $0,001 *$ & 0,686 & 1,455 \\
\hline DSTADM & $-1,210$ & 1,320 & $-0,089$ & $-9,171$ & 6,550 & 0,927 & 1,078 \\
\hline H_TYPE & 0,037 & 0,007 & 0,072 & 5,197 & 2,107 & 0,458 & 2,182 \\
\hline Dependen & ariab & 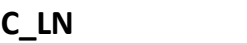 & & & & & \\
\hline
\end{tabular}




\section{References}

Andrew, M., \& Meen, G. (2003). House price appreciation, transactions and structural change in the British housing market: a macroeconomic perspective. Real Estate Economics, 31(1), 99-116.

Bailey, M. J., R. F. Muth, et al. (1963). "A Regression Method for Real Estate Price Index Construction." Journal of the American Statistical Association 58(304): 933-942.

Basu, S., \& Thibodeau, T. G. (1998). Analysis of spatial autocorrelation in house prices. The Journal of Real Estate Finance and Economics, 17(1), 61-85.

Can, A. (1990) “Measurement of Neighborhood Dynamics in Urban House Prices," Economic Geography 66(3) (1990), 254-272.

Can, A., \& Megbolugbe, I. (1997). Spatial dependence and house price index construction. The Journal of Real Estate Finance and Economics, 14(1-2), 203-222.

Case, B., H. O. Pollakowski, et al. (1991). "On Choosing Among House Price-Index Methodologies." Areuea Journal-Journal of the American Real Estate \& Urban Economics Association 19(3): 286-307.

Clapp, J. M. (2003). "A semiparametric method for valuing residential locations: Application to automated valuation." Journal of Real Estate Finance and Economics 27(3): 303-320.

Clapp, J. M., H. J. Kim, et al. (2002). "Predicting spatial patterns of house prices using LPR and Bayesian smoothing." Real Estate Economics 30(4): 505-532.

Coskun, Y., \& Ertugrul, H. M. (2016). House price return volatility patterns in Turkey, Istanbul, Ankara and Izmir. Journal of European Real Estate Research Vol. 9 No. 1, 2016 pp. 26-51.

Çağlayan, E., Koşan, N. İ., \& Astar, M. (2012). An empirical analysis of the determinants of household poverty in Turkey.

Dokmeci, V. and Berkoz, L. (1994) "Transformation of Istanbul from a monocentric to a polycentric city," European Planning Studies 2, 193-205.

Dokmeci, V. and L. Berkoz (2000). "Residential-location preferences according to demographic characteristics in Istanbul." Landscape and Urban Planning 48(1-2): 45-55.

Dokmeci, V., L. Berkoz, et al. (1996). "Residential preferences in Istanbul." Habitat International 20(2): 241251.

Dubin, R. A. (1998). "Predicting house prices using multiple listings data." Journal of Real Estate Finance and Economics 17(1): 35-59.

Ebru, Ç., \& Eban, A. (2011). Determinants of house prices in Istanbul: a quantile regression approach. Quality \& Quantity, 45(2), 305-317.

Eichholtz, P. M. A. (1997). "A long run house price index: The Herengracht Index, 1628-1973." Real Estate Economics 25(2): 175-192.

Gelfand, A. E., M. D. Ecker, et al. (2004). "The dynamics of location in home price." Journal of Real Estate Finance and Economics 29(2): 149-166.

Goodman, A. C. and T. G. Thibodeau (2007). "The spatial proximity of metropolitan area housing submarkets." Real Estate Economics 35(2): 209-232.

Haurin, D. R. and P. H. Hendershott (1991). "House Price Indexes - Issues and Results." Areuea Journal-Journal of the American Real Estate \& Urban Economics Association 19(3): 259-269.

Haurin, D. R., P. H. Hendershott, et al. (1991). "Local House Price Indexes - 1982-1991." Areuea Journal-Journal of the American Real Estate \& Urban Economics Association 19(3): 451-472.

Heikkila, E., Gordon, P., Kim, J. I., Peiser, R. B., Richardson, H. W., \& Dale-Johnson, D. (1989). What happened to the CBD-distance gradient?: land values in a policentric city. Environment and planning A, 21(2), 221232.

Keskin, B. (2008). "Hedonic Analysis of Price in The Istanbul Housing Market." International Journal of Strategic Property Management 12(2): 125-138.

Malpezzi, S. and S. K. Mayo (1997). "Housing and urban development indicators: A good idea whose time has returned." Real Estate Economics 25(1): 1-11.

McMillen, D. P., \& Lester, T. W. (2003). Evolving subcenters: employment and population densities in Chicago, 1970-2020. Journal of Housing Economics, 12(1), 60-81.

McMillen, D. P. (2003). "The return of centralization to Chicago: using repeat sales to identify changes in house price distance gradients." Regional Science and Urban Economics 33(3): 287-304.

Önder, Z., Dökmeci, V., \& Keskin, B. (2004). The impact of public perception of earthquake risk on Istanbul's housing market. Journal of Real Estate Literature, 12(2), 181-194.

Ozus, E., Dokmeci, V., et al. (2007). "Spatial analysis of residential prices in Istanbul." European Planning Studies 15(5): 707-721. 
Özsoy, O., \& Sahin, H. (2009). Housing price determinants in Istanbul, Turkey: An application of the classification and regression tree model. International Journal of Housing Markets and Analysis, 2(2), 167-178.

Peek, J. and Wilcox, J. A. (1991). "The Measurement and Determinants of Single-Family House Prices." Areuea Journal-Journal of the American Real Estate \& Urban Economics Association 19(3): 353-382.

Sun, H., Y. Tu, et al. (2005). "A spatio-temporal autoregressive model for multi-unit residential market analysis." Journal of Real Estate Finance and Economics 31(2): 155-187.

\section{Resume}

Dr. Kerem Yavuz Arslanlı is currently employed at Istanbul Technical University Department of Urban and Regional Planning. He has been worked at ITU Urban and Environmental Planning and Research Center 20022012. He worked at University of Alicante Institute of International Economics in 2010 and Cass Business School Department of Finance in 2011. After completion of his PhD, he has started lectures on, "Real Estate Finance \& Investment" and "Real Estate Modeling and Forecasting", at i.T.Ü. Real Estate Development Master Program. He has academic articles in international/national journals and several conference papers in international conferences. He has been a member of the board of directors of the European Real Estate Society (ERES) and President 2016-17, the leading real estate research and education organization in Europe. (www.eres.org) 